mRS $\leq 2$ at three months was seen in $20 \%$ of the patients. On univariate analysis extravasation was significantly higher in PC compared to anterior circulation (AC) (9\% vs $4 \%$, $\mathrm{p}<0.01)$ as well as post-procedural $\mathrm{sICH}(13 \%$ vs. $4 \%$, $\mathrm{p}=0.01$ ); vessel recanalization (TICI $\geq 2 \mathrm{~b}$ ) was significantly lower in PC compared to AC $(70 \%$ vs $90 \%, \mathrm{p}<0.01)$; mortality rate was significantly higher in patients with $\mathrm{PC}$ compared to AC $(38 \%$ vs $9 \%, \mathrm{p}<0.01)$. On multivariate analysis $\mathrm{AC}$ had a significantly shorter LOS by about three days, compared to PC (coef:-3.04, 95\%CI: -6.05 to $-0.14, p<0.05$ ). There was no difference in odds of achieving a good TICI score. The AC group also had almost four times greater odds of having a good mRS (OR: 3.69, 95\%CI:1.06-12.8, p<0.05). They also had significantly lower odds of mortality, by around eighty-eight percent (OR:0.12, 95\%CI: 0.05-0.31, p<0.01).

Conclusions MT is a safe and efficacious first-line therapy for PC strokes. PC-MT provides a high rate of recanalization without procedural complications. Improvement in functional outcome remains low, and mortality remains high, but with a much better outcome than leaving the disease untreated.

Disclosures A. Sweid: None. K. Hafazalla: None. S. Tjoumakaris: None. V. Xu: None. K. Shivashankar: None. T. Alexander: None. M. Gooch: None. N. Herial: None. N. Chalouhi: None. R. Rosenwasser: None. P. Jabbour: None.

\section{E-105 PREDICTORS OF EXCELLENT OUTCOMES POST THROMBECTOMY IN LARGE VESSEL OCCLUSION WITH MILD STROKES}

${ }^{1} \mathrm{~A}$ Pandhi* ${ }^{1},{ }^{1} \mathrm{~N}$ Goyal, ${ }^{1} \mathrm{G}$ Tsivgoulis, ${ }^{2} \mathrm{~K}$ Malhotra, ${ }^{1} \mathrm{M}$ Ishfaq, ${ }^{3} \mathrm{M}$ Frohler, ${ }^{4} \mathrm{~A}$ Spiotta, ${ }^{4} \mathrm{M}$ Anadani, ${ }^{5} \mathrm{M}$ Psychogios, ${ }^{5} \mathrm{~V}$ Maus, ${ }^{6} \mathrm{~A}$ Siddiqui, ${ }^{6} \mathrm{M}$ Waqas, ${ }^{7} \mathrm{P}$ Schellinger, ${ }^{7} \mathrm{M}$ Groen, ${ }^{1} \mathrm{O}$ Saeed, ${ }^{8} \mathrm{C}$ Krogias, ${ }^{8} \mathrm{D}$ Richter, ${ }^{9} \mathrm{M}$ Saqqur, ${ }^{9} \mathrm{P}$ Bermejo, ${ }^{10} \mathrm{M}$ Mokin, ${ }^{11} \mathrm{R}$ Leker, ${ }^{12} \mathrm{~A}$ Katsanos, ${ }^{13} \mathrm{G}$ Magoufis, ${ }^{13} \mathrm{~K}$ Psychogios, ${ }^{14} \mathrm{~V}$ Lioutas, ${ }^{14} \mathrm{M}$ VanNostrand, ${ }^{15} \mathrm{~V}$ Sharma, ${ }^{16} \mathrm{M}$ Paciaroni, ${ }^{17} \mathrm{~A}$ Rentzos, ${ }^{18} \mathrm{H}$ Shoirah, ${ }^{18} \mathrm{~J}$ Mocco, ${ }^{19} \mathrm{D}$ Hoit, ${ }^{19} \mathrm{~L}$ Elijovich, ${ }^{1} \mathrm{~A}$ Alexandrov, ${ }^{19} \mathrm{~A}$ Arthur. ${ }^{1}$ Neurology, UTHSC, Memphis, TN; ${ }^{2}$ Neurology, West Virginia University, Morgantown, WV; ${ }^{3}$ Cerebrovascular, Vanderbilt University, Nashville, TN; ${ }^{4}$ Neurosurgery, Medical University of South Carolina, Charleston, SC; ${ }^{5}$ Neuroradiology, University Medical Center Göttingen, Gottingen, Germany; ${ }^{6}$ Neurosurgery and Radiology, University of Buffalo, Buffalo, NY; ${ }^{7}$ Neurology and Neurogeriatry, Johannes Wesling Medical Center Minden, Minden, Germany; ${ }^{8}$ Neurology, St. Josef-Hospital, Ruhr University of Bochum, Bochum, Germany; ${ }^{9}$ Neurology, Hammad Medical Center, Doha, Qatar; ${ }^{10}$ Neurosurgery, University of South Florida, Tampa, FL; ${ }^{11}$ Neurology, The Agnes Ginges Center of Neurogenetics, Hadassah-Hebrew University Medical Center, Jerusalem, Israel; ${ }^{12}$ Neurology, National and Kapodistrian University of Athens, 'Attikon' University Hospital, Athens, GREECE; ${ }^{13}$ Acute Stroke Unit, Metropolitan Hospital, Piraeus, Greece; ${ }^{14}$ Neurology, Beth Israel Deaconess Medical Center, Harvard Medical School, Boston, MA; ${ }^{15}$ Neurology, Yong Loo Lin School of Medicine, National University of Singapore, Singapore, Singapore; ${ }^{16}$ Stroke unit, Divisione di Medicina Cardiovascolare, Università di Perugia, Perugia, Italy; ${ }^{17}$ Interventional and Diagnostic Neuroradiology, Department of Interventional and diagnostic Neuroradiology, Gothenburg, Sweden, Gothenburg, Sweden; ${ }^{18}$ Neurosurgery, Mount Sinai Medical Center, New York, New York, NY; ${ }^{19}$ Neurosurgery, UTHSC and Semmes Murphery Clinic, Memphis, TN

10.1136/neurintsurg-2019-SNIS. 180

Background As the randomized controlled trials excluded the patients with emergent large vessel occlusion (ELVO) strokes with low NIHSS $<6$, the efficacy and safety of mechanical thrombectomy (MT) in this cohort is lacking. We sought to explore the predictors of excellent outcomes after MT in this international multicenter study.

Methods Stroke patients with ELVO and NIHSS $<6$ treated with MT were identified from 16 high volume endovascular stroke centers over a 4 year period (2013-2017). Predictors of excellent outcomes post MT were evaluated. Baseline demographic, clinical and procedural variables were obtained.
Successful recanalization was defined as mTICI $2 \mathrm{~b}$ and 3 . Excellent outcomes are defined as modified Rankin Stroke (mRS) scale of $0-1$ at 3 months.

Results Total of 146 patients with low NIHSS ELVO were included in the study. Of those, $95(65 \%)$ patients $(48 \%$ male, 71\% Caucasians, mean NIHSS $3.6 \pm 1.3)$ had excellent outcome (mRS 0-1), while remaining 51 (35\%) patients $(57 \%$ male, $72 \%$ Caucasians, mean NIHSS $3.8 \pm 1.4$ ) had poor outcome (mRS 2-6). The patients who had excellent outcome had lower age at presentation [years, mean (SD) $61.6 \pm 17.2$ vs. $68.9 \pm 18.6$; p: 0.012 ], higher rates of successful recanalization [91.2\% vs. $74 \%$; p: 0.012$]$, and shorter groin puncture to recanalization time [minutes, mean (SD): $43.4 \pm 27.3$ vs. $60.4 \pm 41.5, \mathrm{p}=0.008$ ) compared to poor outcome group. The mean baseline ASPECTS tended to higher in excellent outcome group $(9.3 \pm 1.0$ vs. $8.9 \pm 1.3, \mathrm{p}=0.08)$. In multivariable analyses after adjustment for potential confounders, lower age (OR: $0.96,95 \%$ CI $0.93-0.99, \mathrm{p}=0.034$ ), shorter groin puncture to recanalization time (OR: 0.97 , 95\% CI $0.96-$ $0.99, \mathrm{p}=0.003$ ), and successful recanalization (OR: $11.2,95 \%$ CI $1.5-80.4, p=0.016)$ were independent predictors of excellent outcome at 3 months.

Conclusions Our retrospective multi-center study demonstrates that lower age, shorter groin puncture to recanalization time and successful recanalization were independent predictors of excellent outcomes post MT in ELVO patients with NIHSS $<6$.

Disclosures A. Pandhi: None. N. Goyal: None. G. Tsivgoulis: None. K. Malhotra: None. M. Ishfaq: None. M. Frohler: None. A. Spiotta: None. M. Anadani: None. M. Psychogios: None. V. Maus: None. A. Siddiqui: None. M. Waqas: None. P. Schellinger: None. M. Groen: None. O. Saeed:None. C. Krogias: None. D. Richter: None. M. Saqqur: None. P. Bermejo: None. M. Mokin: None. R. Leker: None. A. Katsanos: None. G. Magoufis: None. K. Psychogios: None. V. Lioutas: None. M. VanNostrand: None. V. Sharma: None. M. Paciaroni: None. A. Rentzos: None. H. Shoirah: None. J. Mocco: None. D. Hoit: None. L. Elijovich: None. A. Alexandrov: None. A. Arthur: None.

\section{E-106 OUTCOME OF MECHANICAL THROMBECTOMY WHEN IV THROMBOLYSIS IS NOT ELIGIBLE}

J Sung*, M Lee, D Lee, H Lee, S Yang. Department of Neurosurgery, St. Vincent's Hospital, The Catholic University of Korea, Suwon, Korea, Republic Of

\subsection{6/neurintsurg-2019-SNIS. 181}

Introduction Mechanical thrombectomy (MT) after intravenous thrombolysis (IVT) is recommended in acute ischemic stroke (AIS) patients with large artery occlusion (LAO). But in cases of ineligible for IVT, MT is the only option. The aim of this study is to evaluate the efficacy and outcome of MT in case of ineligible for IVT.

Method Retrospective analysis was performed in consecutive patients treated between January 2016 and November 2018 for AIS with LAO. Patient demographic data were collected and clinical outcome, procedure details and complication rate were compared.

Results During the period, 80 patients were visited within 4.5 hours from onset, but only 31 underwent MT alone due to contraindication (MT group). And 49 underwent MT combined IVT (MTIVT group). There was no significant 